\title{
Advances in Ice-Templated and Freeze-Casted Ceramics
}

\author{
Sylvain Deville ${ }^{[}$ \\ Laboratoire de Synthèse et Fonctionnalisation des Céramiques, CNRS/Saint-Gobain CREE, Saint-Gobain \\ Research Provence, 84306 Cavaillon, France; sylvain.deville@saint-gobain.com
}

Received: 17 September 2019; Accepted: 20 September 2019; Published: 26 September 2019

Ice-templating, also known as freeze-casting, has become over the past 15 years a well-established materials processing route [1]. The underlying principles—-the segregation and templating of particulate suspensions by growing crystals-are generic, resulting in a variety of ice-templated porous and dense materials. If ceramics (including soils in cold regions! [2]) were among the first ice-templated materials, all types of materials have now been ice-templated, from ceramics to polymers, metals [3], gels, carbon-based materials such as graphene or carbon nanotubes, and even food (cocoa! [4]) and drugs such as ibuprofen [5]. Such broad applicability has accelerated progress and understanding in the field.

Most of the early work focused on assessing the applicability of ice-templating to a new system: what are the requirements for the suspension to be frozen? What do the porous structures looks like (porosity content, pore morphology)? To which extent can the microstructure be adjusted? Is there something unique about such structure that cannot be achieved otherwise? Such work was tedious and yet required for further progress.

Ice-templated ceramics, whether traditional or advanced, have been particularly investigated, for an ever-broadening range of structural or functional properties. Although many proof-of-principle studies have been reported and most of the underlying physics understood, there is still a lot to explore, in particular before ice-templated ceramics and ceramic composites may eventually find their way in applications. Studies in the recent years have focused in particular on two critical aspects:

- Development of processing routes associated to specific functional properties, morphologies, or applications (tubes, membranes, beads, thin films, etc.).

- Assessment of functional properties, in particular in the application environment. However, little attention has been paid so far to reproducibility and reliability.

The papers presented in this topical issue are excellent examples of such recent progress and where the field is going. Su et al. [6] reports how radial-concentric architectures can be obtained by ice-templating. Such complex, bioinspired architectures are difficult to achieve by the traditional processing routes for porous ceramics, and are thus a good example of the benefits of ice-templating.

If most of the ice-templating studies are focused on properties related to the porosity (strength, permeability, pores interconnectivity), Ellis et al. [7] show how ice-templating can also be beneficial for a very different property, thermal expansion, and used ice-templating to prepare a composite material with near-zero thermal expansion. The composite is prepared by ice-templating a first compound $\left(\mathrm{Al}_{2} \mathrm{~W}_{3} \mathrm{O}_{12}\right)$, before infiltrating the porous scaffold with a second phase (PMMA). This strategy has often been used to prepare composite materials for structural applications, with excellent results. This work thus shows that different functional properties can be targeted with this class of materials.

Three of the papers of this issue are focused on demonstrating the benefits of ice-templating for specific applications. Gaudillere et al. [8] investigated how ice-templating can be used to prepare oxygen permeation asymmetric tubular membrane. This particular application has been identified as promising for ice-templated ceramics, with studies reported from different groups $[9,10]$. One of the benefits of 
ice-templating reported here is the possibility to prepare membranes with radial oriented porosity, which lowers the pressure drop across the membrane. Papa et al. [11] investigated geopolymers, a material class on which only few ice-templating studies have been reported, and demonstrate how ice-templated geopolymer-Fe/Mn oxide composites could find application as oxygen carrier. Although not a ceramic system (let's be open!), Rogers et al. [12] reports how MOF/polymer composites could be used for water remediation, and illustrate the proof-of-principle of the approach with the adsorption of an herbicide methylchlorophenoxypropionic acid (MCPP) from aqueous solution. Of particular interest is the recyclability of the materials.

Finally, Niksiar et al. [13] expose in a detailed review paper recent progress made on the application of external fields (electric, magnetic, but also acoustic) to control in situ the microstructure formation in ice-templating processes. Because of the electric surface charges of ceramic particles (and of ice), the application of such fields is an elegant approach to control the interactions between the particles and the moving solidification front as well as the particles organization in the suspension, which impacts the resulting microstructures and architectures. Distinct gradient, core-shell, ring, helical, or long-range alignment of microstructure can thus be achieved. Such structural features have proven useful, in particular to improve the mechanical properties, as they improve the microstructural homogeneity and reduce the overall number of structural defects. A benefit of this approach, typical of ice-templating, is the combination with other processing strategies.

There is still a lot to explore, in particular before ice-templated ceramics and ceramic composites may eventually find their way in industrial applications. In particular, in addition to the points listed above, progress is needed in the following areas:

- Fundamental understanding and control of the process, in particular for the control of textures and of composites microstructures: the distribution and organization of particles (in particular anisotropic particles), the phase distribution, the development of microstructural defects in ice-templated structures. The development of novel strategies, such as reported in the review paper of Niksiar et al. [13], are useful to better understand the physics of ice-templating, which will eventually lead to a better control of the materials processes and properties.

- Combination of ice-templating with traditional ceramic processing and scale up. Although several processing routes have been successfully combined with ice-templating (tape-casting [14], spray drying), many routes can still be explored. Very little effort has been paid to investigate scale-up of the current ice-templating routes, although this will be one of the keys for a successful transfer of these approaches from the lab to successful industrial applications.

There is plenty of room for more freezing studies.

Conflicts of Interest: The author declares no conflict of interest.

\section{References}

1. Deville, S. Freezing Colloids: Observations, Principles, Control, and Use; Springer International Publishing: New York, NY, USA, 2017. [CrossRef]

2. Taber, S. Frost Heaving. J. Geol. 1929, 37, 428-461. [CrossRef]

3. Röthlisberger, A.; Häberli, S.; Spolenak, R.; Dunand, D.C. Synthesis, structure and mechanical properties of ice-templated tungsten foams. J. Mater. Res. 2016, 31, 753-764. [CrossRef]

4. Nguyen, P.T.N.; Ulrich, J. Fast Dispersible Cocoa Tablets: A Case Study of Freeze-Casting Applied to Foods. Chem. Eng. Technol. 2014, 37, 1376-1382. [CrossRef]

5. Witte, A.; Ulrich, J. An Alternative Technology to Form Tablets. Chem. Eng. Technol. 2010, 33, 757-761. [CrossRef]

6. Su, F.; Mok, J.; McKittrick, J. Radial-Concentric Freeze Casting Inspired by Porcupine Fish Spines. Ceramics 2019, 2, 161-179. [CrossRef]

7. Ellis, S.; Romao, C.; White, M. Near-Zero Thermal Expansion in Freeze-Cast Composite Materials. Ceramics 2019, 2, 112-125. [CrossRef] 
8. Gaudillere, C.; Garcia-Fayos, J.; Plaza, J.; Serra, J.M. Ice-Templating for the Elaboration of Oxygen Permeation Asymmetric Tubular Membrane with Radial Oriented Porosity. Ceramics 2019, 2, 246-259. [CrossRef]

9. Liu, T.; Zhao, W.; Wang, Y. Robust Freeze-Cast Bilayer Dual-Phase Oxygen Transport Membrane Targeting Chemical Reactor Application. ACS Appl. Nano Mater. 2018, acsanm.8b00990. [CrossRef]

10. Schulze-Küppers, F.; Unije, U.V.; Blank, H.; Balaguer, M.; Baumann, S.; Mücke, R.; Meulenberg, W.A. Comparison of freeze-dried and tape-cast support microstructure on high-flux oxygen transport membrane performance. J. Memb. Sci. 2018, 564, 218-226. [CrossRef]

11. Papa, E.; Medri, V.; Natali Murri, A.; Miccio, F.; Landi, E. Ice-Templated Geopolymer-Fe/Mn Oxide Composites Conceived as Oxygen Carriers. Ceramics 2019, 2, 148-160. [CrossRef]

12. Rogers, C.; Pun, D.; Fu, Q.; Zhang, H. Fabricating MOF/Polymer Composites via Freeze Casting for Water Remediation. Ceramics 2018, 1, 353-363. [CrossRef]

13. Niksiar, P.; Su, F.Y.; Frank, M.B.; Ogden, T.A.; Naleway, S.E.; Meyers, M.A.; McKittrick, J.; Porter, M.M. External Field Assisted Freeze Casting. Ceramics 2019, 2, 208-234. [CrossRef]

14. Rachadel, P.L.; Souza, D.F.; Nunes, E.H.M.; Dinizda Costa, J.C.; Vasconcelos, W.L. A novel route for manufacturing asymmetric BSCF-based perovskite structures by a combined tape and freeze casting method. J. Eur. Ceram. Soc. 2017, 37, 5249-5257. [CrossRef]

(C) 2019 by the author. Licensee MDPI, Basel, Switzerland. This article is an open access article distributed under the terms and conditions of the Creative Commons Attribution (CC BY) license (http://creativecommons.org/licenses/by/4.0/). 